\title{
New Evidence for the Role of Ethylene in Strawberry Fruit Ripening
}

\author{
Jing-Hua Sun $\cdot$ Jing-Jing Luo $\cdot$ Lin Tian $•$ \\ Chun-Li Li $\cdot$ Yu Xing $\cdot$ Yuan-Yue Shen
}

Received: 16 October 2012 / Accepted: 9 November 2012/Published online: 31 January 2013

(c) The Author(s) 2013. This article is published with open access at Springerlink.com

\begin{abstract}
It has been suggested that the phytohormone ethylene plays a role in strawberry fruit ripening, and new genetic evidence for the role of this hormone in strawberry ripening is provided in this study. The combined analysis of ethylene production and transcripts of the ethylene biosynthesis-related gene FaSAMS1 and the signaling gene FaCTR1 in 'Camarosa' strawberry (Fragaria ananassa) fruit showed that an increase in ethylene production was concomitant with a rise in transcripts of the two genes during fruit red-coloring, suggesting that FaSAMS1 and FaCTR1 might play a role in fruit ripening. Downregulation of the FaSAMSI or FaCTRI transcript via a recently reported tobacco rattle virus-induced gene-silencing technique not only inhibited fruit red-coloring and firmness, but it also promoted ethylene biosynthesis. Furthermore, the latter also affected a series of ethylene-signaling components. Importantly, applied ethephon could promote natural strawberry fruit red-coloring and softening and partially rescue anthocyanin biosynthesis in the two-type RNAi fruit, but could not markedly affect RNAi fruit firmness. These data provide new evidence that FaCTR1 positively
\end{abstract}

Jing-Hua Sun, Jing-Jing Luo, and Lin Tian contributed equally to this work.

Electronic supplementary material The online version of this article (doi:10.1007/s00344-012-9312-6) contains supplementary material, which is available to authorized users.

J.-H. Sun · J.-J. Luo $\cdot$ L. Tian · C.-L. Li · Y. Xing ·

Y.-Y. Shen (ه)

Beijing Key Laboratory of New Technology in Agricultural Application, College of Plant Science and Technology, Beijing

University of Agriculture, No. 7 Beinong Road, Changping

District, Beijing 102206, People's Republic of China

e-mail: sfmn@tom.com regulates strawberry fruit ripening and that ethylene is required for strawberry fruit ripening.

Keywords Ethylene - Strawberry fruit ripening · Constitutive triple response $1(\mathrm{CTR} 1) \cdot S$-adenosyl-Lmethionine synthetase (SAMS) $\cdot$ Virus-induced gene silencing (VIGS)

\section{Introduction}

The gaseous plant hormone ethylene not only plays an important role in various aspects of plant growth and development, including seed germination, organ senescence, and fruit development, it also regulates stress responses to environmental challenge (reviewed by Fluhr and Mattoo 1996). Notably, the effect of ethylene on climacteric fruit ripening and its signaling transduction pathways have been studied extensively in the past decades. Not only was it found that there is an essential role for this hormone in the regulation of climacteric fruit ripening, but a defined model for its mechanism of action was established (reviewed by Gray and others 1994; Giovannoni 2001, 2004; Alexander and Grierson 2002; AdamsPhillips and others 2004; Prasanna and others 2007; Bapat and others 2010; Klee and Giovannoni 2011). Although several previous reports indicated that ethylene is possibly involved in the regulation of nonclimacteric fruit ripening (Cazzonelli and others 1998; Tian and others 2000; El-Kereamy and others 2003; Katz and others 2004; Wechter and others 2008), new genetic evidence for the action of ethylene in ripening has been needed.

A physiological function played by ethylene depends on from its production to action. The ethylene biosynthesis and signaling transduction pathways in the model plant 
Arabidopsis are well defined (supplementary Fig. 1). The former pathways include three committed steps (Thomas and Surdin-Kerjan 1991; Kende 1993; Bleecker and Kende 2000): (1) conversion of methionine to $S$-adenosyl-Lmethionine (SAM) catalyzed by SAM synthetase (SAMS), (2) formation of 1-aminocyclopropane-1-carboxylic acid (ACC) from SAM via ACC synthase (ACS) activity, and (3) conversion of ACC to ethylene through ACC oxidase (ACO). The latter pathways include a series of signaling transductions: Ethylene is perceived by a receptor family (ETR1, ETR2, ERS1, ERS2, or EIN4), which can physically interact with CTR1 (constitutive triple response 1) and consequently recruits CTR1 protein to activate EIN2 by a negative mechanism. This in turn activates a transcriptional cascade involving the EIN3/EIL and ERF transcription factors, and plant development and defense responses are finally evoked (see review by Chen and others 2005; Benavente and Alonso 2006; Zhu and Guo 2008). Because of the vital role of ethylene in triggering tomato fruit ripening, to a large extent this model has been further developed for the fruit (Barry and Giovannoni 2007). Some ripening-related genes, including HMG-CoA reductase, polygalacturonase (PG), pectin methylesterase, ACC synthase, ACC oxidase, phytoene synthase, and NR ethylene receptor, have been confirmed in the fruit (Gray and others 1994; Alexander and Grierson 2002; Bouzayen 2002), not only demonstrating that ACC synthase LeACS2 and ACC oxidase LeACO1 control tomato fruit ethylene production, but also finding that at least six genes encode tomato ethylene receptors (LeETR1-6) that can interact directly with five LeCTRs, of which only tCTR1 (ER50) is induced by both ripening and exogenous ethylene (Klee 2002). Although a model for ethylene biosynthesis and action involved in climacteric fruit ripening had been established in tomato 10 years ago (Alexander and Grierson 2002), whether SAM synthetase, committed in the first step in ethylene biosynthesis, plays a role in fruit ripening to our knowledge remains yet unclear.

In comparison with the progress made in studying ethylene in climacteric fruit, the study of the molecular mechanism of ethylene in nonclimacteric fruit is far behind. With the exception of several other nonclimacteric fruit species, including pineapple (Cazzonelli and others 1998), grapevine (El-Kereamy and others 2003; Chervin and others 2008), citrus (Katz and others 2004), and watermelon (Wechter and others 2008), in which it is suggested that ethylene plays a ripening-regulating role, interestingly, strawberry fruit is the most widely studied system with ethylene regulation underlying nonclimacteric ripening (Hoad and others 1971; Knee and others 1977; Given and others 1988; Abeles and Takeda 1990; Wilkinson and others 1995; Perkins-Veazie and others 1996; Manning 1998; Tian and others 2000; Atta-Aly and others
2000; Aharoni and O'Connell 2002; Balogh and others 2005; Villarreal and others 2010). Although several studies indicate that strawberry fruit does not exhibit a peak in respiration and ethylene production during ripening and that the application of exogenous ethylene to green strawberry fruit has little effect on the rate of ripening (Hoad and others 1971; Knee and others 1977; Abeles and Takeda 1990), some reports have found that strawberry fruit color development and softening are slightly accelerated by ethylene or inhibited by its competitive inhibitor 1-MCP (Wills and Kim 1995; Tian and others 2000; Jiang and others 2001), that some ripening-related genes are at least partly ethylene-dependent (Balogh and others 2005; Villarreal and others 2010), and that an increased synthesis of receptors (FaETR1 and FaERS1) is concomitant with a rise in ethylene level promoted by $\mathrm{FaACO} 1$ and $\mathrm{FaACO} 2$ and a little ethylene might be sufficient to trigger ripeningrelated physiological responses by a negative $\mathrm{C}_{2} \mathrm{H}_{4}$ feedback mechanism (Atta-Aly and others 2000; Trainotti and others 2005). Thus, although much progress has been made toward understanding the role of ethylene in strawberry fruit development, to our knowledge new genetic evidence for the role of this hormone in strawberry fruit ripening is needed.

In this report, the combined analysis of ethylene production and transcripts of the ethylene biosynthesis-related gene FaSAMSI and the signaling gene FaCTRI in 'Camarosa' strawberry implied that FaSAMS1 and FaCTR1 might play a role in fruit ripening. Using our recently reported tobacco rattle virus-induced gene-silencing (VIGS) technique in strawberry fruit (Chai and others 2011; Jia and others 2011), we showed that downregulation of the FaSAMS1 or FaCTR1 transcript could inhibit fruit red-coloring. Interestingly, the retarded red development could be partially rescued by applied ethephon. The results demonstrate that FaCTR1 is a positive regulator and ethylene is a required signaling molecule in strawberry fruit ripening.

\section{Materials and Methods}

\section{Plant Materials}

Octaploid strawberry (Fragaria ananassa cv. 'Camarosa') fruit was used in this study. Strawberry plants were grown under nonheated greenhouse conditions in a Beijing cold winter (average day/night temperature $=23 / 10^{\circ} \mathrm{C}$, 14/10 h light/dark, $70-90 \%$ relative humidity) during 2009-2011. Two hundred small green fruits on 50 strawberry plants were tagged during the first week after anthesis. Fruit developmental stages (small green, big green, degreening, white, initially red, partially red, and 
fully red) were divided for $7,15,20,23,27,31$, and 35 days after anthesis, respectively. Ten fruits of uniform size were sampled at every stage (three replications). The receptacle was cut into small cubes of $0.5-0.8 \mathrm{~cm}^{3}$, then quickly frozen in liquid nitrogen and stored at $-80{ }^{\circ} \mathrm{C}$ until use.

RNA Isolation and cDNA Synthesis

Total RNA was extracted from $10 \mathrm{~g}$ of receptacle of strawberry fruit or infected pulp sectors using a modified CTAB protocol (Jia and others 2008). Genomic DNA was removed by 15 -min incubation at $37{ }^{\circ} \mathrm{C}$ with RNase-Free DNase (TaKaRa, Otsu, Japan) followed by an RNA Clean Purification Kit (BioTeke, Beijing, China). The purity and integrity of the RNA were analyzed by both agarose gel electrophoresis and the $A_{260}: A_{230}$ and $A_{260}: A_{280}$ ratios. To generate first-strand cDNA, 3- $\mu$ g aliquots of total RNA were reverse-transcribed using a universal primer $\left[5^{\prime}-\right.$ AAGCAGTGGTATCAACGCAGAGTAC $(\mathrm{T})_{30}$ VN-3', where $\mathrm{N}=\mathrm{A}, \mathrm{C}, \mathrm{G}$, or $\mathrm{T}$ and $\mathrm{V}=\mathrm{A}, \mathrm{G}$, or $\mathrm{C}]$ supplied by a SMART $^{\mathrm{TM}}$ RACE cDNA Synthesis Kit (TaKaRa) according to the manufacturer's protocols. The experiment was done with three replications.

Cloning of FaSAMS1 and FaCTRl Genes and RT-PCR Analysis

The cDNA obtained above was used as a template for amplification of FaSAMS1 and FaPYRI genes with the following primers: FaSAMS1, forward: 5'-ATGGAGAC TTTCCTATTCACATCTG- $3^{\prime}$ and reverse: $5^{\prime}$-TTAAGAC TGAGGCTTCTCCCAC-3'; FaCTR1, forward: 5'-ATGG AAATGATAACAACAACAAGG- $3^{\prime}$ and reverse: $5^{\prime}$-TCA GGTGAGTATTGGCAAGTCTG-3'. PCR was performed under the following conditions: $94{ }^{\circ} \mathrm{C}$ for $5 \mathrm{~min}$, followed by 30 cycles of $94{ }^{\circ} \mathrm{C}$ for $30 \mathrm{~s}, 60^{\circ} \mathrm{C}$ for $30 \mathrm{~s}$, and $72{ }^{\circ} \mathrm{C}$ for $1 \mathrm{~min}$, with a final extension at $72{ }^{\circ} \mathrm{C}$ for an additional $10 \mathrm{~min}$. The PCR products were ligated into a pMD19-T vector and subsequently transformed into Escherichia coli DH5a. Positive colonies were selected, amplified, and sequenced by Invitrogen China (Shanghai, China). For PCR analysis of the transcripts of the two genes, the cDNA was used as a template for PCR amplification through 25 cycles. The experiment was done with three replications.

\section{SYBR ${ }^{\circledR}$ Real-time RT-PCR}

Total RNA was isolated from control fruit or RNAi fruit as described above. For real-time PCR, the reactions $(20 \mu \mathrm{l})$ contained $10 \mu \mathrm{l} \mathrm{SYBR}{ }^{\circledR}$ Premix Ex Taq (TaKaRa), $0.4 \mu \mathrm{l}$ forward-specific primer, $0.4 \mu \mathrm{l}$ reverse-specific primer, and
$2 \mu \mathrm{l}$ cDNA templates. The mixture was placed in an iQ5 Sequence Detector (Bio-Rad, Hercules, CA), and DNA amplification was conducted using the following thermocycling program: $95^{\circ} \mathrm{C}$ for 2 min, followed by 40 cycles of $94{ }^{\circ} \mathrm{C}$ for $20 \mathrm{~s}, 54{ }^{\circ} \mathrm{C}$ for $20 \mathrm{~s}$, and $72{ }^{\circ} \mathrm{C}$ for $30 \mathrm{~s}$, followed by 71 cycles increasing from $60 \mathrm{C}$ to $95^{\circ} \mathrm{C}$ with an increment of $0.5{ }^{\circ} \mathrm{C}$ per cycle for $30 \mathrm{~s}$. Actin was used as a reference gene. Relative gene expression was analyzed by real-time PCR and $2^{-\triangle \triangle C T}$ method analysis (Livak and Chmittgen 2001). The experiment was done with three replications.

The primers used for real-time PCR were as follows: SAMS: sense, 5'-ACATTGAGCAGCAGAGC-3'; antisense, $5^{\prime}$-GGGTTTCATCAGTGGC-3';

CTRI: sense, $5^{\prime}$-ATTTTGGTCTTTCCCGTTTAA- $3^{\prime}$; antisense, $5^{\prime}$-ACTTCTGGTGCCATCCATTCA-3';

ETRI: sense, 5'-TTGTAAATCTTATGGAGGGGC-3'; anti-

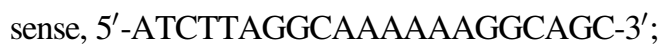

ERS1: sense, 5'-TATTCCTCGTATTTCACCAAG-3'; antisense, $5^{\prime}$-TACTGCAACTGTCACATATCGC-3';

EIN2: sense, $5^{\prime}$-GGGAAGGTTGTAATTTGGAGA-3'; antisense, $5^{\prime}$-AAGCATGGAGACATTGGAGT-3';

EIN3: sense, 5'-GTGAGTTCGTTCAGTGTCC-3'; antisense, 5'-GAGTTCGTTCAGTGTCCTT-3';

CHS: sense, 5'-GAGCAAACAACGAGAACACG-3'; antisense, $5^{\prime}$-GCTGTCAAGGCCATTAAGGA-3';

PG1: sense, 5'-GACAGAGTGAAAAATTCCTTAG- $3^{\prime}$; antisense $5^{\prime}$-GGACTGGGTTAGCAAAATTATTC-3'; Actin: sense, $5^{\prime}$-TGGGTTTGCTGGAGATGAT- $3^{\prime}$; antisense, 5'-CAG TAGGAGAACTGGGTGC-3'.

\section{Construction of Virus Vectors and Agroinfiltration}

The pTRV1 and pTRV2 VIGS vectors (described by Liu and others 2002) were kindly provided by Dr. Liu Yu-Le of Qinghua University. A 515-bp cDNA fragment of FaSAMSI was amplified using the primers 5'-TACTTGATG CTTGCCTGGA GCAG-3' (sense) and 5'-CATCATGC TGGGTGGAGATAAGAA- $3^{\prime}$ (antisense). A 453-bp FaCTRI cDNA fragment was amplified using the primers $5^{\prime}$-TGACAAGTGCCTGATGGGTT- $3^{\prime}$ (sense) and $5^{\prime}$-CAC GGTAGATCAATTGAGTCA GC- $3^{\prime}$ (antisense). The two amplified fragments were inserted into the pMD19-T vector (TaKaRa Bio), digested with EcoR1 and BamH1, and inserted into the EcoR1-BamH1-cut pTRV2 viral vector. Agrobacterium strain GV3101 containing pTRV1, pTRV2, and the pTRV2 derivative pTRV2-FaSAMS1 ${ }_{515}$ or pTRV2$\mathrm{FaCTR} 1_{453}$ was used for RNAi. Agroinoculation and syringe inoculation were performed as described by both $\mathrm{Fu}$ and others (2005) and Chai and others (2011). Ten uniformly sized fruits were used for both the treatment-gene-VIGS test 
and the control-empty-vector-VIGS test. The experiment was done with three replications.

Probe Preparation and Southern Hybridization

Digoxigenin (DIG)-labeled probes were synthesized using a PCR-DIG Probe Synthesis Kit (Roche Diagnostics, Indianapolis, IN), with primers specific to the cloned FaSAMSI (forward: 5'-GTTGGTCTAGATGCCGATAA-3' and reverse: $5^{\prime}$-GGGTGGAGATAAGAACAGTG-3') and FaCTR1 (forward: 5'-GCTTCTGAGCCAGGTCCCC-3' and reverse: 5'-CCACTACCGTCCCATCCAT- ${ }^{\prime}$ ). The procedures of Southern hybridization analysis were performed as Chai and others (2011) described.

\section{Ethephon Treatment}

According to the methods described by Villarreal and others (2010), ethephon treatment of FaSAMS1- and FaCTRI-RNAi fruit and natural $\mathrm{Wt}$ fruit was performed by application of $7 \mathrm{mM}$ ethephon solution, and ethephon-free solution on natural Wt fruit was used as a control. Ten fruits were used for each treatment. These fruits were dipped in the required concentration for $5 \mathrm{~min}$ and then dried under shade. After the treatment, the fruits were kept at $20{ }^{\circ} \mathrm{C}$ for 3 days. The experiment was done with three replications.

Determination of Ethylene Production, Firmness, and Anthocyanin Content

Ten uniform strawberry fruits of each stage were selected and placed in 1-1 glass jars for $1 \mathrm{~h}$ at $20^{\circ} \mathrm{C}$. One milliliter of the jar headspace gas was withdrawn and injected into a gas chromatograph with a flame ionization detector and an activated alumina column (model 6890 N, Agilent, Santa Clara, CA, USA). The ethylene produced $\left(\mathrm{nl} \mathrm{g}^{-1}\right.$ fresh weight $[\mathrm{FW}] \mathrm{h}^{-1}$ ) was analyzed using the following conditions: chromatograph column included HP-5 (5 \% phenyl methyl siloxane) and a 30-m capillary alumina column (Agilent $19091 \mathrm{~J}-413$ ); temperatures of $80{ }^{\circ} \mathrm{C}$ for the column and $150{ }^{\circ} \mathrm{C}$ for the detector were used; the rate of the

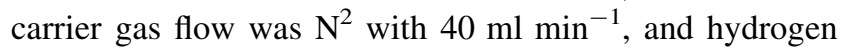
pressure of $0.6 \mathrm{~kg} \mathrm{~cm}^{-2}$ was used. The experiment was done with three replications.

Ten uniform strawberry fruits were used for the detection of firmness and anthocyanin content. Flesh firmness was analyzed on two sides of each fruit using a GY-4 fruit penetrometer (Digital Force Gauge, Shanghai, China). The strength of flesh firmness was recorded as $\mathrm{N} \mathrm{cm}^{-2}$. The anthocyanin content was determined by a spectrophotometer according to the methods described by Villarreal and others (2010). The experiment was done with three replications.

\section{Results}

Firmness and Anthocyanin Content Variation in Developmental Strawberry Fruit

According to recent reports (Chai and others 2011; Jia and others 2011), the development of 'Camarosa' strawberry fruit was divided into seven stages: small green (SG), big green (BG), degreening (DG), white (Wt), initially red (IR), partially red (PR), and fully red (FR) which occurred for $7,15,20,23,27,31$, and 35 days after anthesis in a nonheated greenhouse in cold winter (Fig. 1a). Figure 1 shows that the firmness values $\left(\mathrm{N} \mathrm{cm}^{-2}\right)$ declined slowly and maintained relatively high levels within a range of $45-26 \mathrm{~N} \mathrm{~cm}^{-2}$ from SG to Wt fruit (Fig. 1b), whereas the anthocyanin content held at extremely low levels (Fig. 1c). In contrast, after fruit red-coloring, the firmness values sharply declined and remained at relatively low levels in a range of $1-4 \mathrm{~N} \mathrm{~cm}^{-2}$ (Fig. 1b), whereas the anthocyanin content increased drastically (Fig. 1c). These results suggest that the event of fast softening concomitant with rapid red-coloring might represent a sign of the onset of strawberry fruit ripening.

\section{Cloning and Characterization of FaSAMSI} and FaCTRI

To clone the FaSAM and FaCTR1 genes from 'Camarosa' strawberry fruit, Arabidopsis SAMS1 (At1g02500) and CTR1 genes (At5g03730) were used to BLAST in a strawberry gene library (https://strawberry.plantandfood. co.nz/index.html) and high homology was found in gene loci 24556 and 30145, respectively. Based on these nucleotide sequences, the specific primers (named FaSAMS1: forward, 5'-ATGGAGACTTTCCTATTCA CATCTG- ${ }^{\prime}$; reverse, 5' ${ }^{\prime}$-TTAAGACTGAGGCTTCTCCC AC-3'; and FaCTR1: forward, 5'-ATGGAAATGATAA CAACAACAAGG-3'; reverse, 5'-TCAGGTGAGTATTG GCAAGTCTG- $3^{\prime}$ ) were used to clone both FaSAMS1 and FaCTRI coding sequences. Our results showed that the 1,182- and 2,538-bp cDNA sequences encode deduced 393 and 845 amino acids of FaSAMS1 (supplementary Fig. 2) and FaCTR1 (supplementary Fig. 3), respectively, were isolated. A putative $S$-adenosylmethionine synthetaseconserved domain in FaSAMS1 (supplementary Fig. 4a) and a protein serine/threonine kinase-conserved domain in FaCTR1 (supplementary Fig. 4b) were detected by homology analysis using the FaSAMS1 and FaPYR1 proteins, respectively, found on a NCBI website (http:// blast.ncbi.nlm.nih.gov/Blast.cgi), suggesting that the putative strawberry FaSAMS1 and FaCTRI genes were cloned successfully. Genomic Southern analysis showed that the strawberry genomic DNA contains one copy of FaCTRl 
Fig. 1 Firmness and anthocyanin changes in developmental strawberry fruit. a Changes in fruit size and color. b Changes of firmness. c Changes in anthocyanin. Error bars represent the SE $(n=3)$
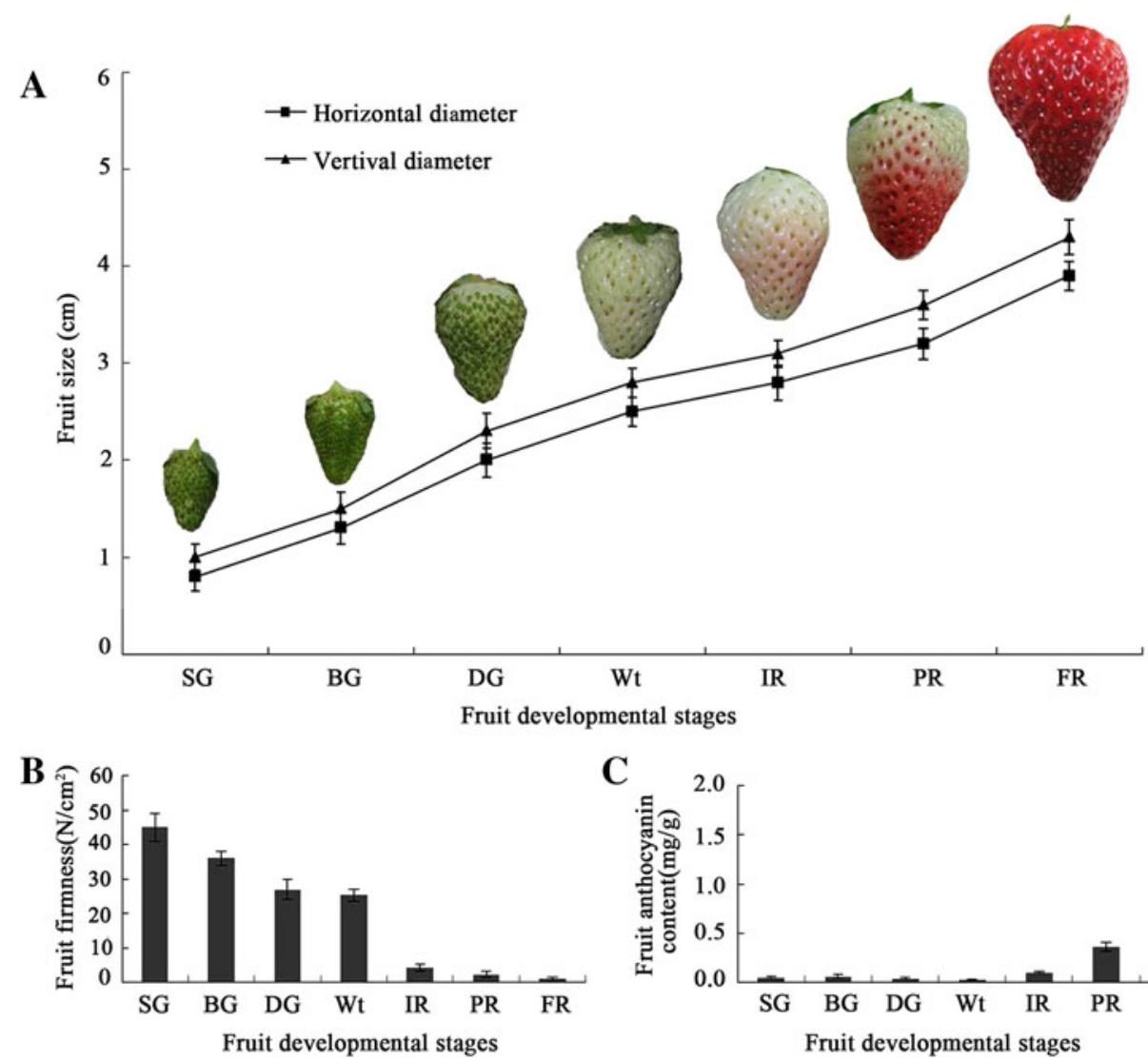

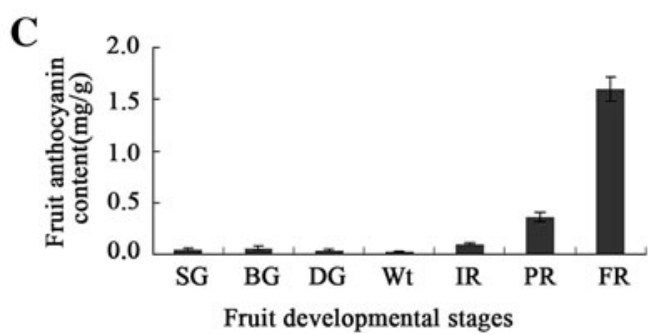

(supplementary Fig. 4c) and two members of FaSAMS1 (supplementary Fig. 4d).

\section{Downregulation of Ethylene Biosynthesis FaSAMS1}

Expression Inhibits Strawberry Ripening

To explore whether FaSAMS1 is involved in the regulation of 'Camarosa' strawberry fruit ripening, first, the combined analysis of FaSAMS1 transcripts and ethylene levels in the seven stages of fruit development was performed. The results showed that the mRNA expression levels of FaSAMS1 rapidly declined before the $\mathrm{Wt}$ stage and then increased slowly and significantly after the Wt stage (Fig. 2a). In contrast, ethylene production rapidly increased before the $\mathrm{Wt}$ stage and then increased slowly and markedly after the Wt stage (Fig. 2b). These trends between FaSAMS1 transcripts and ethylene production imply that the first rapid emission of ethylene in green fruit could result from factors other rather than FaSAMS1. The second slow production of ethylene during fruit red-coloring could result from FaSAMS1, suggesting that FaSAMS1 might be related to the regulation of fruit ripening.

To further assess the role of FaSAMS1 in strawberry fruit ripening, we generated pTRV1- and pTRV2FaSAMS1 $_{515}$ RNAi fruits using our recently reported tobacco rattle virus-induced gene silencing (VIGS, Jia and others 2011; Chai and others 2011) technique with the white stage fruit. Two weeks after inoculation, the surface of the control fruits turned fully red (Fig. 2c); in contrast, the inoculated sector on the surface of the RNAi fruits remained white (Fig. 2d). Real-time PCR and semiquantitative RT-PCR analyses showed that the expression of FaSAMS1 was significantly downregulated at transcription levels in the RNAi fruit compared with that in control fruit inoculated with Agrobacterium containing empty viral TRV vectors (Fig. 2e). These results indicate that FaSAMS1 plays a role in strawberry fruit ripening.

\section{Downregulation of an Ethylene Signaling Component} FaCTR1 Expression Retards Strawberry Ripening

To explore whether FaCTR1 is involved in the regulation of 'Camarosa' strawberry fruit ripening, analysis of the mRNA expression levels of FaCTRl was carried out in the seven stages of fruit development. The results showed that the mRNA expression levels of FaCTRl had rapid increases before and after the Wt stage (Fig. 3a), suggesting that FaCTR1 might be involved in strawberry fruit ripening. To further confirm this notion, we generated pTRV1- and pTRV2-FaCTR $1_{453}$ RNAi fruit using Wt fruits via the VIGS technique (Chai and others 2011). Two weeks after inoculation, the surface of the control fruit 


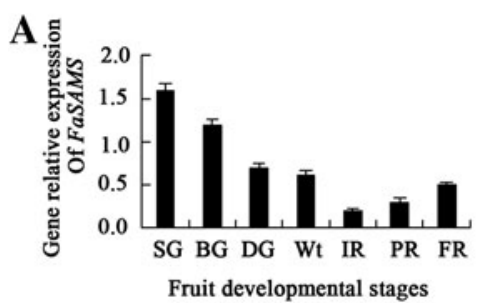

B

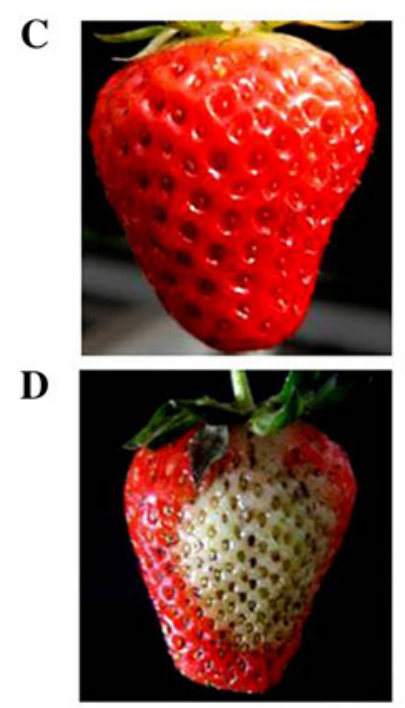

$\mathbf{E}$
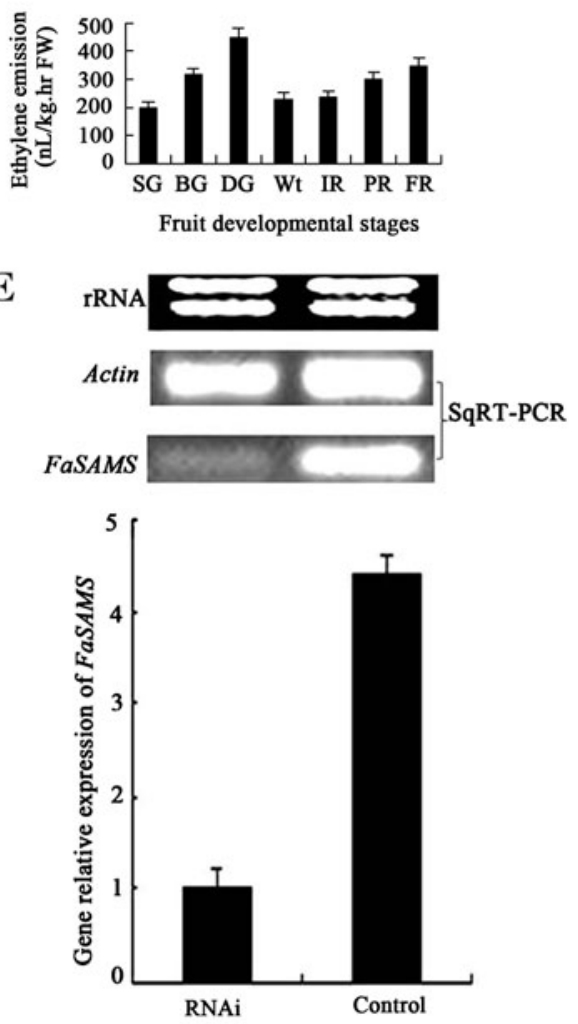

Fig. 2 Changes in FaSAMS1 transcripts and ethylene production during strawberry fruit development and silencing of FaSAMS1 by VIGS in the fruit. a Change in FaSAMS1 transcripts in developmental fruit. b Change in ethylene release in developmental fruit. c-e Virusinduced FaSAMS1 gene silencing in strawberry fruit: white fruit still attached to the plant were inoculated with Agrobacterium containing tobacco rattle virus (TRV) alone (control) or TRV carrying a

turned fully red (Fig. 3b); in contrast, the inoculated sector on the surface of the RNAi fruit remained white (Fig. 3c). Real-time PCR and semiquantitative RT-PCR analyses showed that the expression of FaCTRI was significantly downregulated at transcription levels in the RNAi fruits in comparison with that in the control fruit inoculated with Agrobacterium containing empty viral TRV vector (Fig. 3d). These results indicate that FaCTR1 positively regulates strawberry fruit ripening.

Downregulation of $\mathrm{FaCTRl}$ Gene Alters Expression of a Set of Ethylene-responsive Genes Related to Fruit Color and Firmness

Real-time PCR analysis showed that the transcripts of a set of possible ethylene-responsive genes were significantly altered in the downregulated-FaCTRI RNAi fruit compared to that in control fruit, such as ERS1 (Clark and others 1998), EIN2 (Alonso and Stepanova 2004), EIN3 (Chao and others 1997), ERF1 (Solano and others 1998), PGl

FaSAMS1 fragment (RNAi). Two weeks after inoculation, phenotypes were observed for the control fruit (c) and RNAi fruit (d). The semiquantitative RT-PCR and real-time PCR analyses of the FaSAMS1 transcripts in receptacles of the control (c) or RNAi fruit (e) were conducted, respectively. The rRNA indicates the loading control of the RNA samples stained with ethidium bromide. Actin was used as the internal control. Error bars represent the SE $(n=3)$

(García-Gago and others 2009), and CHS (Jia and others 2011). Notably, the ethylene receptor gene ERSI was markedly upregulated and SMASI was not significantly altered, whereas the others were all downregulated in FaCTRl RNAi fruit (Fig. 4). These results indicated that the partial disruption of $F a C T R I$ expression could have inhibited fruit anthocyanin biosynthesis and firmness and led to uncolored and unsoftened RNAi fruit (Fig. 3), in which anthocyanin content was decreased by $83 \%\left(0.21 \pm 0.09 \mathrm{mg} \mathrm{g}^{-1}\right.$ in control fruit and $0.036 \pm 0.01 \mathrm{mg} \mathrm{g}^{-1}$ in RNAi fruit) and firmness was increased by $95 \%\left(1.1 \pm 0.7 \mathrm{~N} \mathrm{~cm}^{-2}\right.$ in control fruit and $23.9 \pm 1.6 \mathrm{~N} \mathrm{~cm}^{-2}$ in RNAi fruit). Taken together, these data are consistent with a positive role for FaCTR 1 in the ethylene regulation of ripening.

Partial Disruption of the FaSAM or FaCTRl Gene Alters the Responsiveness of RNAi Fruit to Ethephon

To further confirm the role of ethylene on strawberry fruit ripening, first we measured ethylene production in RNAi 

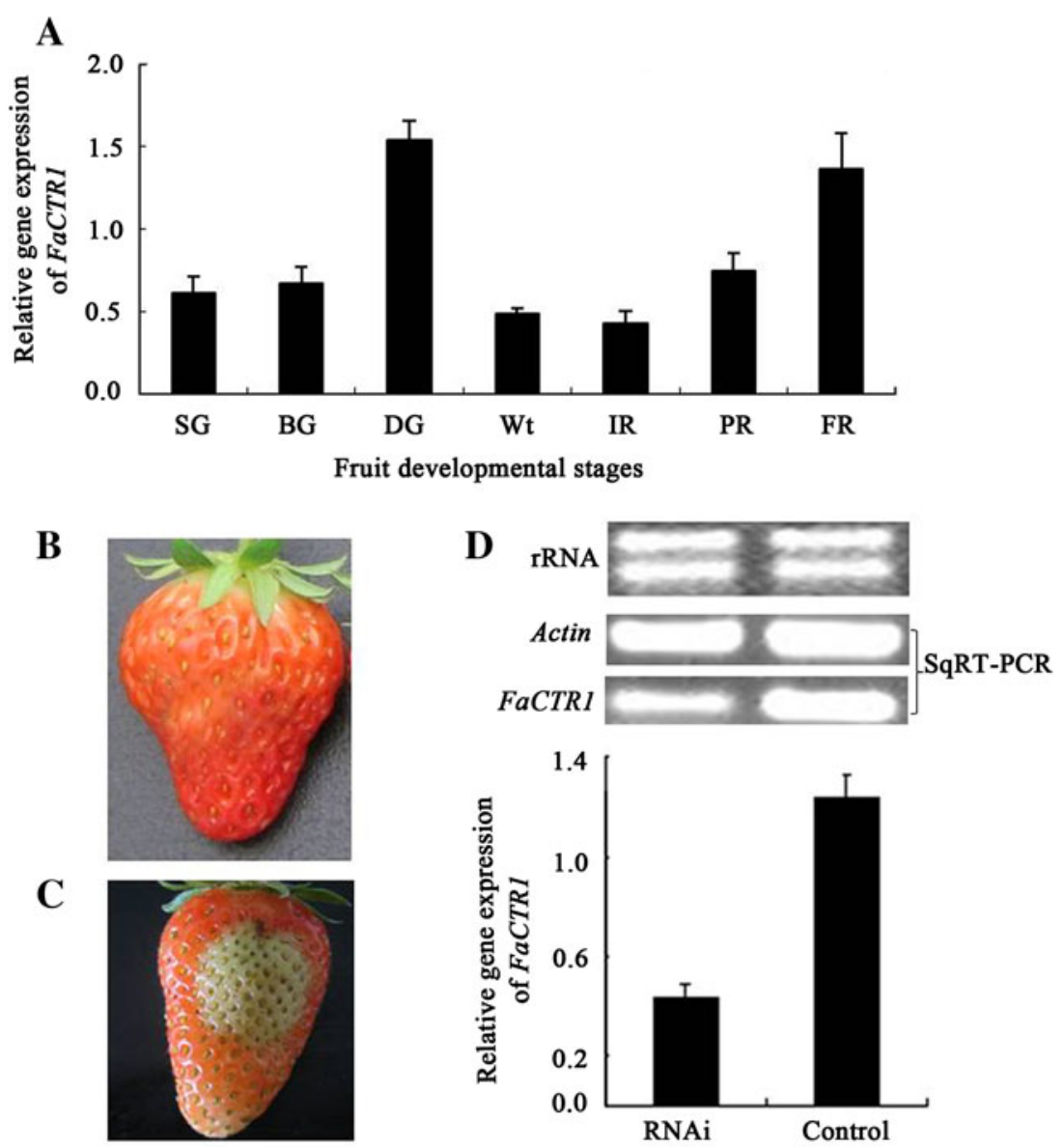

Fig. 3 Changes in FaCTR1 transcripts during strawberry fruit development and silencing of FaCTR1 by VIGS in the fruit. a Change of FaCTR1 transcripts in developmental fruit. b-d Virusinduced $F a C T R 1$ gene silencing in strawberry fruit: white fruit still attached to the plant were inoculated with Agrobacterium containing tobacco rattle virus (TRV) alone (control) or TRV carrying a FaCTRl fragment (RNAi). Two weeks after inoculation, phenotypes

were observed for the control fruit (b) and RNAi fruit (c). The semiquantitative RT-PCR and real-time PCR analysis of the FaCTRI transcripts in receptacles of the control (c) or RNAi fruit (d) were conducted, respectively. The rRNA indicates the loading control of the RNA samples stained with ethidium bromide. Actin was used as the internal control. Error bars represent the SE $(n=3)$

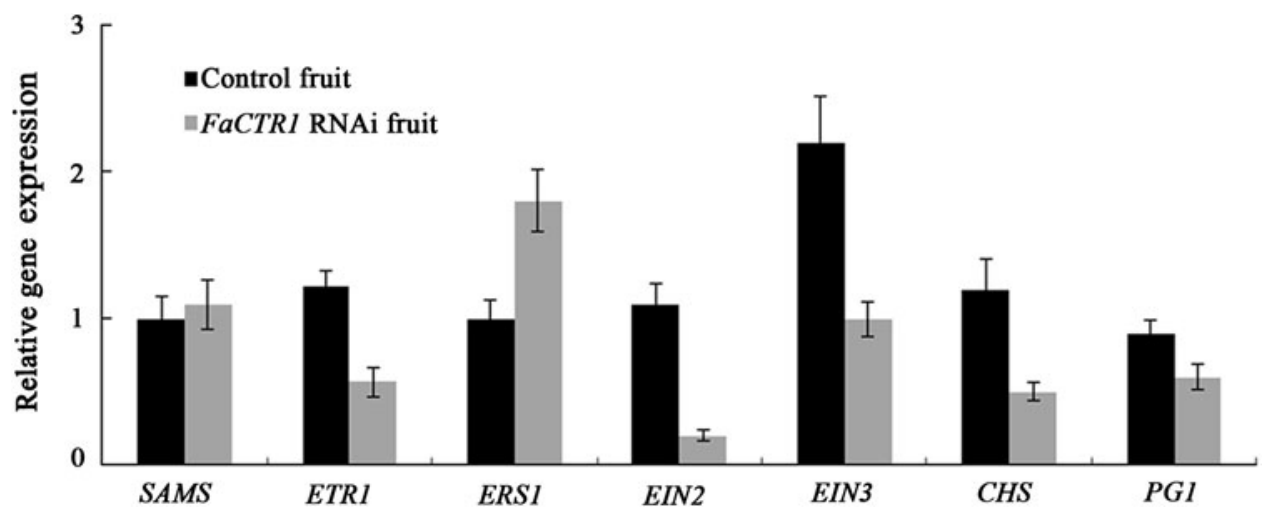

Fig. 4 Transcriptional changes in ethylene-signaling genes in RNAi fruit. The mRNA expression levels of ethylene-signaling genes in FaCTR1-silenced RNAi fruit (downregulated by $77 \%$ ) and control

red fruit were detected by real-time PCR. Actin mRNA was used as an internal control. The error bars represent the SE $(n=3)$ 


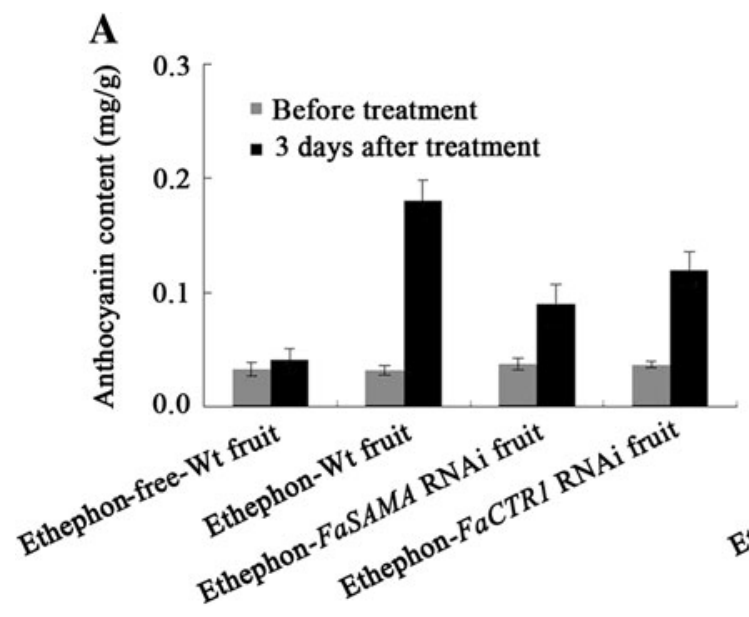

Fig. 5 Effect of ethephon on anthocyanin content and firmness of the FaSAMS- and FaCTRI-RNAi fruits in vitro. Ethephon treatment of FaSAMS- and FaCTRI-RNAi fruit and natural Wt fruit was performed by application of solutions of ethephon with $7 \mathrm{mM}$

fruit, and natural white fruits were used as controls. GLC analysis showed that ethylene production in FaSAMS1RNAi fruit (white section), FaCTRI-RNAi fruit (white section), and control fruit was, on average, $612 \pm 45$, $435 \pm 37$, and $237 \pm 28 \mathrm{nl} \mathrm{kg}^{-1} \mathrm{FW} \mathrm{h}^{-1}$, respectively. The data demonstrated that ethylene production was significantly upregulated in the two-type RNAi fruit, especially FaSAMSI-RNAi fruit. Second, we investigated the effects of ethephon (7 $\mathrm{mM})$ on both color and firmness of RNAi fruit (treatment) and natural white fruit (control) in vitro. The results showed that 3 days after treatment, the anthocyanin contents of ethephon-treated FaSAMSI-RNAi fruit, FaCTRI-RNAi fruit, natural white fruit, and free ethephon-treated control fruit increased by 24, 463, 139, and $224 \%$, respectively (Fig. 5a), and firmness correspondingly decreased by $25,88,19$, and $27 \%$, respectively (Fig. 5b). These data indicate that ethephon can promote natural strawberry fruit red-coloring and softening and partially rescue anthocyanin biosynthesis in the two-type RNAi fruit, but the firmness was not markedly affected.

\section{Discussion}

\section{FaSAMS1 Plays a Role in Strawberry Fruit Ripening}

In plants, nearly $80 \%$ of cellular methionine is converted to SAM by SAM synthetase (SAMS) (Ravanel and others 1998). In addition to being a precursor of ethylene, SAM may serve as a methyl group donor in DNA, RNA, protein, and lipid methylation reactions and lignin or polyamine biosynthesis (Tabor and Tabor 1984; Yang and Hoffman 1984; Heby and Persson 1990; Kende 1993; Wang and
B

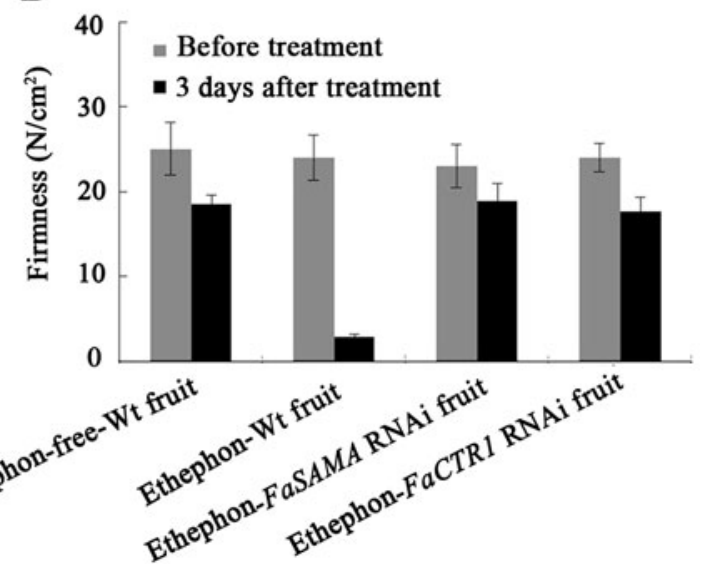

concentration. Ethephon-free treatment of natural Wt fruit was used as a control. a The effect of treatment on anthocyanin content. $\mathbf{b}$ The effect of treatment on firmness. Error bars represent the SE $(n=3)$

others 2002). This suggests that there might be a large SAM pool in plants and SAMS is not believed to be a key regulatory step in ethylene production (Yang and Hoffman 1984). Thus, less attention has been paid to the role of SAMS in fruit development. Although a previous report showed that SAMS transcripts in climacteric Actinidia chinensis fruit were induced during the late ethylene burst as part of the methionine salvage pathway (Whittaker and others 1997), the defined role of SAMS in nonclimacteric fruit remains unclear.

In the present study, we provide indirect and direct evidence that FaSAMS plays a role in strawberry fruit ripening. The indirect evidence is that the mRNA expression levels of FaSAMSI declined rapidly before the Wt stage and increased slowly and significantly after the Wt stage, whereas ethylene production increased rapidly before the Wt stage and increased slowly and markedly after the Wt stage (Fig. 2), suggesting that FaSAMS might be involved in ripening rather than in early development. A possible explanation is that in green berries, the SAM pool might be large and thus lead to higher ethylene production under the lower expression of the SAMS gene; in red-coloring berries, when most of the SAM pool is exhausted by metabolism, the amount of SAM might become a limiting factor for ethylene biosynthesis. Consequently, the function of SAMS should be evoked again to restore the SAM pool, which meets with ethylene biosynthesis. It is notable that this situation is similar to the results for Actinidia chinensis fruit reported by Whittaker and others (1997). The direct evidence is that downregulation of the FaSAMSI transcripts by VIGS could lead to the uncolored RNA interference (RNAi) fruit (Fig. 2), demonstrating that FaSAMS1 plays a role in fruit ripening. 
FaCTR1 is a Potential Positive Regulator for Strawberry Fruit Ripening

A report by Kieber and others (1993) showed that the Arabidopsis CTRI gene is constitutively expressed and acts as a negative regulator of ethylene signaling in seed germination. It is interesting to note that the tomato plant contains five CTR genes ( $t C T R 1-5$, Alexander and Grierson 2002), among which only $t C T R 1$ is induced by ripening in tomato fruit (Bouzayen 2002; Klee 2002). In the 'Rosa' hybrid, RhCTRI expression increases during flower senescence, whereas $R h C T R 2$ is constitutively expressed during flower development (Müller and others 2002). In the present study, we found that FaCTRl is induced by both degreening and redcoloring (Fig. 3), suggesting that FaCTR1 might be involved in strawberry fruit development. Downregulation of the FaCTR1 transcripts by VIGS could lead to the uncolored RNA interference (RNAi) strawberry fruit (Fig. 3), a set of ethylene-responsive genes (Fig. 4), and feedback regulation of ethylene levels, demonstrating that FaCTR1 is a potential positive regulator for strawberry fruit ripening.

\section{Ethylene is Required for Strawberry Fruit Ripening}

Characterization of the role of ethylene in nonclimacteric fruit is intriguing. Over the past decades, the effect of ethylene on nonclimacteric fruit, in particular, strawberry, has been studied extensively (Hoad and others 1971; Knee and others 1977; Given and others 1988; Abeles and Takeda 1990; Wilkinson and others 1995; Perkins-Veazie and others 1996; Cazzonelli and others 1998; Manning 1998; Atta-Aly and others 2000; Tian and others 2000; Aharoni and O'Connell 2002; El-Kereamy and others 2003; Katz and others 2004; Balogh and others 2005; Chervin and others 2008; Wechter and others 2008; Villarreal and others 2010). Although a role for ethylene in strawberry fruit was suggested by pharmacological and transcriptional tests (Wills and Kim 1995; Atta-Aly and others 2000; Tian and others 2000; Jiang and others 2001; Balogh and others 2005; Trainotti and others 2005; Villarreal and others 2010), new evidence about the role of ethylene in nonclimacteric fruit ripening was needed.

In the present study, we have provided physiological and molecular evidence that ethylene plays a role in strawberry fruit ripening: (1) although a climacteric fruit-like ethylene peak did not occur in 'Camarosa' strawberry fruit development, a slow increase in ethylene emission was coupled with red-coloring (Fig. 2); (2) downregulation of FaSAMS1 expression not only inhibited strawberry red-coloring (Fig. 2), it also promoted feedback regulation of ethylene levels; (3) downregulation of FaCTRI expression not only retarded strawberry red-coloring (Fig. 3), it also affected both ethylene levels and a series of ethylene-signaling components (Fig. 4), demonstrating that FaCTR1 positively regulates strawberry fruit ripening; (4) ethephon could significantly promote natural white fruit red development and partially rescued both FaCTRI- and FaSAMA1-RNAi fruit anthocyanin biosynthesis, but it could not rescue the two-type RNAi fruit firmness in vitro (Fig. 5). These unconventional and distinct responses of FaCTRI - and FaSAMS1-RNAi fruit to ethephon imply the complexity of ethylene regulation of strawberry fruit ripening. Subsequently, more VIGS tests using ethylene receptors and ACC synthase or oxidase may provide more data to decipher the complex molecular mechanism of ethylene in the regulation of the fruit ripening.

Acknowledgments We thank Prof. Liu Yu-le for pTRV vectors. This work was supported financially by the National Key Basic Research '973' Program of China (grant No. 2012CB126306), the National Science Foundation of China (grant Nos. 30971977, 31272144), and the Newstar of Science and Technology Supported by Beijing Metropolis (Grant No. Z111105054511048).

Open Access This article is distributed under the terms of the Creative Commons Attribution License which permits any use, distribution, and reproduction in any medium, provided the original author(s) and the source are credited.

\section{References}

Abeles FB, Takeda F (1990) Cellulase activity and ethylene in ripening strawberry and apple fruits. Sci Hortic 42:269-275

Adams-Phillips L, Barry C, Giovannoni J (2004) Signal transduction systems regulating fruit ripening. Trends Plant Sci 9:331-338

Aharoni A, O'Connell A (2002) Gene expression analysis of strawberry achene and receptacle maturation using DNA microarrays. J Exp Bot 53:2073-2087

Alexander L, Grierson D (2002) Ethylene biosynthesis and action in tomato: a model for climacteric fruit ripening. J Exp Bot 3:2039-2055

Alonso JM, Stepanova AN (2004) The ethylene signaling pathway. Science 306:1513-1515

Atta-Aly MA, Brecht JK, Huber DJ (2000) Ethylene feedback mechanisms in tomato and strawberry fruit tissues in relation to fruit ripening and climacteric patterns. Postharvest Biol Technol 20:151-162

Balogh A, Koncz T, Tisza V, Kiss E, Heszky L (2005) The effect of $1-\mathrm{MCP}$ on the expression of several ripening-related genes in strawberries. Hortic Sci 40:2088-2090

Bapat VA, Trivedi PK, Ghosh A, Sane VA, Ganapathi TR, Nath P (2010) Ripening of fleshy fruit: molecular insight and the role of ethylene. Biotechnol Adv 28:94-107

Barry CS, Giovannoni JJ (2007) Ethylene and fruit ripening. J Plant Growth Regul 26:143-159

Benavente LM, Alonso JM (2006) Molecular mechanisms of ethylene signaling in Arabidopsis. Mol BioSyst 2:165-173

Bleecker AB, Kende H (2000) Ethylene: a gaseous signal molecule in plants. Ann Rev Cell Dev Biol 16:1-40

Bouzayen M (2002) Ripening-associated transcriptional regulation in the tomato. A case of cross-talk between ethylene and auxin? Comp Biochem Physiol A 132:S97 
Cazzonelli CI, Cavallaro AS, Botella R (1998) Cloning and characterization of ripening-induced ethylene biosynthetic genes from nonclimacteric pineapple (Ananas comosus) fruits. Aust J Plant Physiol 25:513-518

Chai YM, Jia HF, Li CL, Dong QH, Shen YY (2011) FaPYR1 is involved in strawberry fruit ripening. J Exp Bot 62:5079-5089

Chao Q, Rothenberg M, Solano R, Roman G, Terzaghi W, Ecker JR (1997) Activation of the ethylene gas response pathway in Arabidopsis by the nuclear protein ethylene-insensitive 3 and related proteins. Cell 89:1133-1144

Chen YF, Etheridge N, Schaller GE (2005) Ethylene signal transduction. Ann Bot 95:901-915

Chervin C, Tira-Umphon A, Terrier N, Zouine M, Severac D, Roustan JP (2008) Stimulation of the grape berry expansion by ethylene and effects on related gene transcripts, over the ripening phase. Physiol Planta 134:534-546

Clark KL, Larsen PB, Wang X, Chang C (1998) Association of the Arabidopsis CTR1 Raf-like kinase with the ETR1 and ERS ethylene receptors. Proc Natl Acad Sci USA 95:5401-5406

El-Kereamy A, Chervin C, Roustan JP (2003) Exogenous ethylene stimulates the long-term expression of genes related to anthocyanin biosynthesis in grape berries. Physiol Planta 119:175-182

Fluhr R, Mattoo AK (1996) Ethylene biosynthesis and perception. Crit Rev Plant Sci 15:5-6

Fu DQ, Zhu BZ, Zhu HL, Jiang WB, Luo YB (2005) Virus-induced gene silencing in tomato fruit. Plant J 43:299-308

García-Gago JA, Posé S, Muñoz-Blanco J, Quesada MA, Mercado JA (2009) The polygalacturonase FaPGl gene plays a key role in strawberry fruit softening. Plant Signal Behav 4:766-768

Giovannoni JJ (2001) Molecular biology of fruit maturation and ripening. Annu Rev Plant Physiol Plant Mol Biol 52:725-749

Giovannoni JJ (2004) Genetic regulation of fruit development and ripening. Plant Cell 16:S170-S180

Given NK, Venis MA, Grierson D (1988) Hormonal regulation of ripening in the strawberry, a non-climacteric fruit. Planta 174:402-406

Gray JE, Picton S, Giovannoni JJ, Grierson D (1994) The use of transgenic and naturally occurring mutants to understand and manipulate tomato fruit ripening. Plant Cell Environ 17:557-571

Heby O, Persson L (1990) Molecular genetics of polyamine synthesis in eukaryotic cells. Trends Biochem Sci 15:153-158

Hoad GV, Anderson HM, Guttridge CG, Sparks TR (1971) Ethylene and the ripening of strawberry fruits. Bristol Univ Long Ashton Res Stat Ann Rep, pp 33-34

Jia HF, Zhu XQ, Jin XS, Shen YY (2008) An effective method and its modifications for isolation of high-quality total RNA from fruit pulps. J Agric Sci Technol 2:58-62

Jia HF, Chai YM, Li CL, Lu D, Luo JJ, Qin L, Shen YY (2011) Abscisic acid plays an important role in the regulation of strawberry fruit ripening. Plant Physiol 157:188-199

Jiang Y, Joyce DC, Terry LA (2001) 1-Methylcyclopropene treatment affect strawberry fruit decay. Postharvest Biol Technol 23:227-232

Katz E, Lagunes PM, Riov J, Weiss D, Goldschmidt EE (2004) Molecular and physiological evidence suggests the existence of a system II-like pathway of ethylene production in nonclimacteric citrus fruit. Planta 219:243-252

Kende H (1993) Ethylene biosynthesis. Annu Rev Plant Physiol Plant Mol Biol 44:283-307

Kieber JJ, Rothenberg M, Roman G, Feldmann KA, Ecker JR (1993) CTR1, a negative regulator of the ethylene response pathway in Arabidopsis, encodes a member of the raf family of protein kinases. Cell 72:427-444

Klee HJ (2002) Control of ethylene-mediated processes in tomato at the level of receptors. J Exp Bot 53:2057-2063

Klee HJ, Giovannoni JJ (2011) Genetics and control of tomato fruit ripening and quality attributes. Annu Rev Genet 45:41-59
Knee M, Sargent JA, Osborne DJ (1977) Cell wall metabolism in developing strawberry fruits. J Exp Bot 28:377-396

Liu YL, Schiff M, Dinesh-Kumar SP (2002) Virus-induced gene silencing in tomato. Plant J 31:777-786

Livak KJ, Schmittgen TD (2001) Analysis of relative gene expression data using real-time quantitative PCR and the 2- $\Delta \Delta \mathrm{CT}$ method. Methods 25:402-408

Manning K (1998) Isolation of a set of ripening-related genes from strawberry: their identification and possible relationship to fruit quality traits. Planta 205:622-631

Müller R, Owen CA, Xue ZT, Welander M, Stummann BM (2002) Characterization of two CTR-like protein kinases in Rosa hybrida and their expression during flower senescence and in response to ethylene. J Exp Bot 53:1223-1225

Perkins-Veazie PM, Huber DJ, Brecht JK (1996) In vitro growth and ripening of strawberry fruit in the presence of ACC, STS or propylene. Ann Appl Biol 128:105-116

Prasanna V, Prabha TN, Tharanathan RN (2007) Fruit ripening phenomena: an overview. Crit Rev Food Sci Nutr 47:1-19

Ravanel S, Gakiere B, Job D, Douce R (1998) The specific features of methionine biosynthesis and metabolism in plants. Proc Natl Acad Sci USA 95:7805-7812

Solano R, Stepanova A, Chao Q, Ecker JR (1998) Nuclear events in ethylene signaling: a transcriptional cascade mediated by ethylene-insensitive3 and ethylene-response-factor1. Genes Dev 12:3703-3714

Tabor CW, Tabor H (1984) Methionine adenosyl transferase ( $S$-adenosylmethionine synthetase) and $S$-adenosylmethionine decarboxylase. Adv Enzymol 56:251-282

Thomas D, Surdin-Kerjan Y (1991) The synthesis of the two $S$-adenosyl-methionine synthetases is differently regulated in Saccharomyces cerevisiae. Mol Gen Genet 226:224-232

Tian MS, Prakash S, Elgar HJ, Young H, Burmeister DM, Ross GS (2000) Responses of strawberry fruit to 1-methylcyclopropene (1-MCP) and ethylene. Plant Growth Regul 32:83-90

Trainotti L, Pavanello A, Casadoro G (2005) Different ethylene receptors show an increased expression during the ripening of strawberries: does such an increment imply a role for ethylene in the ripening of these non-climacteric fruits? J Exp Bot 56:2037-2046

Villarreal NM, Bustamante CA, Civello PM (2010) Effect of ethylene and 1-MCP treatments on strawberry fruit ripening. J Sci Food Agric 90:683-689

Wang K, Li H, Ecker J (2002) Ethylene biosynthesis and signaling networks. Plant Cell 14:S131-S151

Wechter WP, Levi A, Harris KR, Davis AR, Fei Z, Katzir N, Giovannoni JJ, Salman-Minkov A, Hernandez A, Thimmapuram J, Tadmor Y, Portnoy V, Trebitsh T (2008) Gene expression in developing watermelon fruit. BMC Genomics 9:275

Whittaker DJ, Smith GS, Gardner RC (1997) Expression of ethylene biosynthetic genes in Actinidia chinensis fruit. Plant Mol Biol 34:45-55

Wilkinson JQ, Lanahan MB, Conner TW, Klee HJ (1995) Identification of mRNAs with enhanced expression in ripening strawberry fruit using polymerase chain reaction differential display. Plant Mol Biol 27:1097-1108

Wills RBH, Kim GH (1995) Effect of ethylene on postharvest life of strawberries. Postharvest Biol Technol 6:249-255

Yang SF, Hoffman NE (1984) Ethylene biosynthesis and its regulation in higher-plants. Annu Rev Plant Physiol Plant Mol Biol 35:155-189

Zhu Z, Guo H (2008) Genetic basis of ethylene perception and signal transduction in Arabidopsis. J Integr Plant Biol 50:808-815 